authority populations as being crucial to success.

To ensure that the new health service works for populations as well as for individual patients a director of public health must be an executive member of every new health authority, alongside the general manager and the finance director. Otherwise, directors of public health and health authorities will be unable to fulfil all the requirements of $\mathrm{HC}(88) 64$ and the white paper.

ROGER SIMPSON

ELIZABETH HAWORTH NICKY WHITAKER

PETER DIXON

Department of Public Health Medicine.

West Berkshire Health Authority.

Reading $R(i 3+\mathrm{EJ}$

I Simpson RJ, McCloskey BG. Sub-regional revenue allocations and SMRs: progress towards equity? Hospital and Health and SMRs: progress towards
Sereices Review 1987;83:165-7.

2 Department of Health. Health of the population: responsibilities for health authorities. London: DHSS, 1988. (HC $(88) 64$.)

SIR,- The white paper appears to suffer from two major omissions and one potential major contradiction.

Firstly, there appears to be no intention to improve the information system. At present there is no way in which the NHS at any level can obtain reliable data about the prevalence of disease in any local population group. Even data on incidence are not sufficiently detailed or reliable because the current methods of coding and the level of staff who do it leave something to be desired. It is therefore difficult for planners to assess the required level of provision of health services.

Secondly, there is very little reference to preventive medicine and public health generally. It is axiomatic that reduced disease prevalence would reduce the requirement for curative health services - for example, tuberculosis in the United Kingdom - and we still have major problems with, for example, ischaemic heart and other vascular disease and lung neoplasms.

Finally, charges for capital assets are to be introduced. These will presumably form a significant cost element in the financial calculations which are to be a prominent feature of the yet again reformed NHS. There are several ways in which such charges could be calculated. ${ }^{1-3}$ Account will have to be taken of inflation, local differences in property costs, and equipment depreciation. If calculated on true local values the charges for property in urban areas, especially central London, will make all procedures rather more expensive in the major urban hospitals, considerably to their detriment under the present plans.

It may be that these problems will be addressed in the detailed further papers to be produced. If they are not I would suggest that we are not going to see any real advance in the effectiveness of the NHS following these new plans.

London N6

P M BRETLAND

1 Owler LWJ, Brown JL. Wheldon's cost accounting. 15th ed. London: Pitman, 1983:chapter 13.

2 Bretland PM. Costing imaging procedures. Br $\mathcal{F}$ Radiol 1988;61: 54-61.

3 Bretland PM. Costs of nuclear medicine. Nuclear Medicine Communications 1988;9:37-42.

\section{What do psychiatric inpatients really want?}

SIR, - We are puzzled by the thrust of the article by $\mathrm{Mr}$ Keith McIntyre and colleagues. ${ }^{1}$ We do not find their results surprising, but we are surprised by their recommendations based on them.

Readers of the article could be forgiven for believing that the authors advocate treatment that is decided purely by the subjective opinion of the patient. On this basis much extravagant research is being carried out unnecessarily.

Freedom to leave hospital is certainly valued by all sorts of patients. Those with paranoid schizophrenia wish to trace their persecutors, those with mania wish (to their relatives' dismay) to run up their debts yet further, and those with dependence syndromes wish to seek their drugs. Is this a good use of inpatient facilities?

Talking to a doctor is certainly desired by many patients with psychosis. They may believe that the doctor has some special role in their delusional world. Is this good use of staff?

We suggest that the patients are usually in hospital because they need to be, because they are temporarily incompetent to make optima decisions about their own actions, and because they require nursing. This view may quite rightly be called paternalistic. The alternative is to permit autonomy to those whose judgment is impaired, to collude with thoughts and actions that have proved so disastrous for them, and to allow them to get into still greater difficulties. We also suggest that the doctors are not talking to the patients because they are where they need to be-talking productively with the majority of the mentally ill, who have retained or regained sufficient judgment and autonomy to be out of hospital. That is a better use of resources.

\section{Susan Britton Wills Unit,
Bristol General Hospital,}

Bristol BS1 6SY

University of Bristol

Bristol BS2 8BZ

1 McIntyre K, Farrell M, David AS. What do psychiatric in patients really want? Br Med J 1989;298:159-60. (21 January.)

\section{Risks of dependence on benzodiazepine drugs}

SIR,-Dr Heather Ashton states that she has "observed" that long use of benzodiazepines results in increasing anxiety during regular intake and gives references to herself. ${ }^{\prime}$ Perusing the publications she specifies, I found expressions of opinion that a minority of patients had anxiety that was worse than they had had before other doctors had started the treatment. Dr Ashton did not have data from before treatment was given, her observations were non-blinded, and there were no controls. No substitution by placebo was used in withdrawal, and no numerical research rating were made. Caution might therefore temper hypotheses. Psychiatrists and general practitioners often see patients who present with anxiety and who have exacerbations and remissions over many years.

Controlled research shows that the only commonly prescribed benzodiazepine that cause anxiety is triazolam. In reports to the Food and Drug Administration this was true of triazolam in $0.5 \mathrm{mg}$ and $0.25 \mathrm{mg}$ doses and not of flurazepam or temazepam. ${ }^{2}$ In Edinburgh we have extended our earlier finding of an increase in measured anxiety during use of triazolam ${ }^{3}$ and have recorded daily anxiety ratings when placebos were given and then when 40 subjects regularly took triazolam $0.5 \mathrm{mg}$ for 25 nights, 40 took lormetazepam $2 \mathrm{mg}$, and 40 continued on placebo. Those who took triazolam gradually became more anxious, whereas those who took placebo or lormetazepam did not. ${ }^{+}$When we had earlier used the same sensitive devices to measure anxiety in a similar population neither nitrazepam $5 \mathrm{mg}$ nor lormetazepam $2 \mathrm{mg}$ taken for six months caused an increase in anxiety. In the United States Rickels et al used well established tools to measure anxiety and found that diazepam taken for 22 weeks far from enhancing anxiety caused a sustained reduction, with no evidence of tolerance. ${ }^{6}$

Triazolam differs from other benzodiazepine derivatives in its structure and much shorter life; in regular use it can indeed cause anxiety. There is simply no evidence that this is true of most benzodiazepines. As indicated above there is some evidence against the hypothesis for flurazepam, temazepam, diazepam, nitrazepam, and lormetazepam.

IAN OSWALD

University Department of Psychiatry,

Royal Edinburgh Hospital,

Edinburgh EH10 5HF

1 Ashton H. Risks of dependence on benzodiazepine drugs: a major problem of long term treatment. Br Med J 1989;298: 103-4. (14 January.)

2 Bixler EO, Kales A, Brubaker BH, Kales JD. Adverse reactions to benzodiazepine hypnotics: spontaneous reporting system. Pharmacology 1987;35:286-300.

3 Morgan K, Oswald I. Anxiety caused by a short-life hypnotic. BrMed f 1982:284:942.

4 Adam K, Oswald I. Can a rapidly-eliminated hypnotic cause daytime anxiety? Pharmacopsychiatry (in press).

5 Oswald I, French C, Adam K, Gilham J. Benzodiazepine hypnotics remain effective for 24 weeks. Br Med J 1982;284: hypnotics $860-3$.

6 Rickels K, Case WG, Downing RW, Winokur A. Long-term diazepam therapy and clinical outcome. JAMA 1983;250:
$767-71$.

SIR,-The papers by Dr Peter Tyrer and Dr Heather Ashton and the editorial comment by Professor Peter Rubin refer to the risks of using benzodiazepine drugs. ${ }^{12}$ What are the benefits? Who are the patients for whom "short term alleviation of acute states of anxiety or insomnia" is required? Half a dozen vignettes of such patients in five or six lines each would be helpful to doctors like myself who never seem to see them.

Patients sometimes ask for tablets at the beginning of a consultation; after careful inquiry into the sources of anxiety and a discussion of how these might be remedied they do not usually repeat the request. I cannot remember the last time I prescribed a benzodiazepine, and I have not felt the lack of them in treating a large number of patients with anxiety symptoms. I had given up the barbiturates for treating anxiety before the benzodiazepine drugs came in so perhaps that is why I did not succumb to using them. I note that yet another group of drugs is beginning to be promoted for the relief of anxiety and they, no doubt, will go through the same cycle.

Patients who are suffering from acute distress as a result of events in their lives require as a rule sympathetic support, and W H Threthowan coined the phrase "pills for personal problems" as prophylaxis against the irrationality of offering help in chemical terms where more rational - that is, more scientific-methods of intervention would be appropriate. So often these drugs do no more than convert anxious but clear headed people into anxious but woozy headed people less able to deal practically with their problems. ${ }^{3}$ At a symposium about these drugs two years ago the chairman, Anthony Clare, spoke of his concern for the "medicalisation of what are seen to be social problems" and referred to the drugs being "potentially hazardous." 4 Most of the other speakers referred to the risks and dangers but no one seemed to draw the obvious conclusion that there is no use for the benzodiazepine drugs in the treatment of anxiety. ${ }^{56}$

Dr Ashton refers to patients developing further symptoms while taking these drugs. I would add to her list panic attacks, phobias, and insomnia and have frequently seen these disappear in a few weeks when the drugs are stopped. Similar symptoms occur in heavy drinkers and are relieved when they stop drinking.

These papers refer to people who "keep on taking" the tablets and who demand them; we should remember that in ordinary practice no one takes the tablets unless someone prescribes them. 